Article

\title{
Impact of Vitiation on a Swirl-Stabilized and Premixed Methane Flame
}

\author{
Mao Li * (i), Yiheng Tong, Jens Klingmann and Marcus Thern \\ Department of Energy Sciences, Lund University, Ole Römers väg 1, SE-221 00 Lund, Sweden; \\ yiheng.tong@energy.lth.se (Y.T.); jens.klingmann@energy.lth.se (J.K.); marcus.thern@energy.lth.se (M.T.) \\ * Correspondence: mao.li@energy.lth.se; Tel.: +46-076-555-4514
}

Received: 3 September 2017; Accepted: 28 September 2017; Published: 10 October 2017

\begin{abstract}
Vitiation refers to the condition where the oxygen concentration in the air is reduced due to the mix of dilution gas. The vitiation effects on a premixed methane flame were investigated on a swirl-stabilized gas turbine model combustor under atmospheric pressure. The main purpose is to analyze the combustion stability and $\mathrm{CO}$ emission performance in vitiated air and compare the results with the flame without vitiation. The $\mathrm{N}_{2}, \mathrm{CO}_{2}$, and $\mathrm{H}_{2} \mathrm{O}$ (steam) were used as the dilution gas. Measurements were conducted in a combustor inlet temperature of $384 \mathrm{~K}$ and $484 \mathrm{~K}$. The equivalence ratio was varied from stoichiometric conditions to the LBO (Lean Blowout) limits where the flame was physically blown out from the combustor. The chemical kinetics calculation was performed with Chemkin software to analyze the vitiation effects on the flame reaction zone. Based on the calculation results, the changes in the temperature gradient, $\mathrm{CO}$ concentration, and active radicals across the flame reaction zone were identified. The time-averaged $\mathrm{CH}$ chemiluminescence images were recorded and the results indicated the features of the flame shape and location. The $\mathrm{CH}$ signal intensity provided the information about the heat-release zone in the combustor. The combustion $\mathrm{LBO}$ limits were measured and the vitiation of $\mathrm{CO}_{2}$ and $\mathrm{H}_{2} \mathrm{O}$ were found to have a stronger impact to elevate the LBO limits than $\mathrm{N}_{2}$. Near the LBO limits, the instability of the flame reaction was revealed by the high-speed chemiluminescence imaging and the results were analyzed by FFT (Fast Fourier Transfer). CO emission was measured with a water-cooled probe which is located at the exit of the combustor. The combustion vitiation has been found to have the compression effect on the operation range for low $\mathrm{CO}$ emission. However, this compression effect could be compensated by improving the combustor inlet temperature.
\end{abstract}

Keywords: vitiation effects; $\mathrm{LBO}$ limits; $\mathrm{CO}$ emission; $\mathrm{CO}_{2}$ dilution; steam dilution

\section{Introduction}

Due to environmental problems, the low emission combustion technologies have attracted considerable attention. In the combustion concept, with the consideration of reducing pollutant emissions, the operating condition where combustion happens in the air with reduced oxygen concentration, so-called vitiated air, is commonly encountered. Regarding the combustion research field, the vitiated air refers to the air containing additional gas which is neither fuel nor oxygen. The air vitiation is commonly achieved by the recirculation of exhaust gas into the fresh air stream (referred to as exhaust gas recirculation (EGR), the burning of landfill gas (approximately forty to sixty percent is methane, with the remainder being mostly $\mathrm{CO}_{2}$ ), and the use of a staged combustion system, e.g., with additional fuel injection after the primary reaction zone. Vitiated air generally includes the combustion products such as $\mathrm{CO}_{2}, \mathrm{H}_{2} \mathrm{O}, \mathrm{CO}, \mathrm{NO}_{x}$ and unburned hydrocarbons, along with $\mathrm{N}_{2}$ and $\mathrm{O}_{2}$.

The vitiated air has been used in many practical combustion systems, e.g., gas turbine combustors, furnaces, and piston engines, in order to reduce pollutant emissions and improve thermal efficiency [1]. 
Compared to normal air, vitiated air has a lower oxygen concentration and contains a different composition which impacts the chemical and physical properties of the reactant mixtures. Hence, the process of fuel oxidation and flame propagation could be affected, which could make the burning of the fuel in vitiated air differ from what happens in pure air. For most combustion devices, the primary vitiation species are $\mathrm{N}_{2}, \mathrm{CO}_{2}$, and $\mathrm{H}_{2} \mathrm{O}$ (steam). Therefore, investigation of the vitiation effects of $\mathrm{N}_{2}$, $\mathrm{CO}_{2}$, and $\mathrm{H}_{2} \mathrm{O}$ are the main objectives of the current work.

In combustion applications like EGR, $\mathrm{N}_{2}, \mathrm{CO}_{2}$, and $\mathrm{H}_{2} \mathrm{O}$ constitute the majority of the vitiated air. $\mathrm{CO}_{2}$ and $\mathrm{H}_{2} \mathrm{O}$ were found to have a strong effect on chemical kinetics, while $\mathrm{N}_{2}$ was found to predominantly have the thermal effect [2,3]. The previous study results indicated that $\mathrm{CO}_{2}$ had an inhibiting effect on the fuel oxidation process [2,4]. More analysis on the chemical effect of $\mathrm{CO}_{2}$ vitiation showed that the reduction of the fuel oxidation rate was primarily determined by the reaction $\mathrm{CO}+\mathrm{OH} \leftrightarrow \mathrm{CO}_{2}+\mathrm{H}[5,6]$. Hence a negative effect on the combustor operation range with low $\mathrm{CO}$ concentration can be expected due to the $\mathrm{CO}_{2}$ vitiation. $\mathrm{H}_{2} \mathrm{O}$ vitiation was found to have a positive chemical kinetic effect due to its contribution to the increase of $\mathrm{H}$ and $\mathrm{OH}$ radicals which come from the reaction step $\mathrm{O}+\mathrm{H}_{2} \mathrm{O} \leftrightarrow \mathrm{OH}+\mathrm{OH}$ [7-9] and $\mathrm{H}_{2} \mathrm{O} \leftrightarrow \mathrm{H}+\mathrm{OH}$ (the dissociation of the steam under high temperature) [10]. The thermal effect of the vitiation results in a reduction of the flame temperature, which makes the vitiated combustion a feasible method for achieving $\mathrm{NO}_{\mathrm{x}}$ reduction. $\mathrm{CO}$ emission has been studied in oxyfuel combustion where fuel is burned in $\mathrm{O}_{2} / \mathrm{CO}_{2}$ circumstance. The results showed that $\mathrm{CO}_{2}$ had a significant effect on the increase of $\mathrm{CO}$ concentration [11]. The $\mathrm{H}_{2} \mathrm{O}$ vitiation effect on $\mathrm{CO}$ was also examined and the results showed that the $\mathrm{CO}$ did not seem to be affected significantly [12]. The vitiation effect of $\mathrm{N}_{2}$ and $\mathrm{CO}_{2}$ on the $\mathrm{LBO}$ limits of the methane flame was investigated, and the results showed that $\mathrm{CO}_{2}$ had a stronger effect on the $\mathrm{LBO}$ increase [13]. A similar effect on LBO limits was observed in methane combustion with steam vitiation [14].

According to the previous work, few experimental investigation results were exhibited to compare the effects of the primary vitiation species, e.g., $\mathrm{N}_{2}, \mathrm{CO}_{2}$, and $\mathrm{H}_{2} \mathrm{O}$. Hence, in present work, the vitiation effects of $\mathrm{N}_{2}, \mathrm{CO}_{2}$, and $\mathrm{H}_{2} \mathrm{O}$ were investigated with a swirl-stabilized gas turbine model combustor under atmospheric pressure. Measurements were conducted at the conditions where $10 \%$, $20 \%$, and $30 \%$ mole fraction of the air was substituted by $\mathrm{N}_{2}, \mathrm{CO}_{2}$, and $\mathrm{H}_{2} \mathrm{O}$ (steam), respectively. Chemical kinetics calculations were performed to understand the vitiation effects on the flame reaction zone by using the Chemkin software [15] and the GRI-mech 3.0 mechanism [16]. Time-averaged $\mathrm{CH}$ chemiluminescence images were captured to evaluate the flame shapes, anchored location, and intensity of the heat-release. The LBO limits of flame with and without vitiation were examined and compared to two combustor inlet temperatures $(384 \mathrm{~K} / 484 \mathrm{~K})$. The flame instability prior to LBO was recorded by using the high-speed broadband chemiluminescence. $\mathrm{CO}$ emissions were measured at the combustor exit with a water-cooled probe. The current paper contributes to a better understanding of the vitiated flame on the stable and low CO operation, and the results will bolster the development of environmentally friendly combustion technologies.

\section{Experimental Facilities}

\subsection{Experimental and Operating Configuration}

The flow paths and experimental setup are shown in Figure 1. There are two air flows, one fuel flow, and three vitiation gas flows which can be supplied into the combustor. The air fed into the combustor was supplied from a pressurized lab air source. The air from both the axial direction and the tangential direction were controlled and measured by using differential pressure mass flow controllers (MCR250, Alicat Scientific, Tucson, AZ, USA). The methane fuel with $99.98 \%$ purity was supplied from the gas cylinder. A differential pressure mass flow controller (MCR50, Alicat Scientific, Tucson, AZ, USA) was used to measure and control the fuel flow. Then, the methane was mixed with the air flow from the tangential direction. The vitiation gas $\left(\mathrm{CO}_{2}, \mathrm{~N}_{2}\right.$, and steam) was injected into the tangential flow at the upstream location of the tangential heater. $\mathrm{CO}_{2}$ and $\mathrm{N}_{2}$ were supplied 
from pressurized gas bottles. Steam was provided by a steam generator which contains ten Omega LDC00261 low-density cartridge heaters with a total maximum electrical power of $3 \mathrm{~kW}$. Adjustment of the steam flow could be achieved by controlling the water flow with a precision water flow controller (LC series, Alicat Scientific, Tucson, AZ, USA). An auto-tune temperature and process controller (CN63200-F1-AL, Omega, Stamford, CT, USA) was used so that the steam temperature at the outlet of the steam generator could be controlled. Before coming into the combustor, the blends of the reactants were mixed in the swirler which was followed by a mixing tube of $60 \mathrm{~mm}$. The required equivalence ratios $(\Phi)$ can be achieved by adjusting the methane flow. The equivalence ratio used in current work was defined:

$$
\Phi=\frac{\dot{m}_{\text {fuel }} / \dot{m}_{\text {oxidizer }}}{\left(\dot{m}_{\text {fuel }} / \dot{m}_{\text {oxidizer }}\right)_{\text {stoi }}}
$$

where, $i m$ denotes the mass flow rate and suffix stoi represents the stoichiometric condition. The combustor inlet temperature could be adjusted by using the feedback-controlled air heaters (Sureheat Jet, Sylvania, Exeter, NH, USA) with a power of $8 \mathrm{~kW}$. The combustor inlet temperature was detected by a K-type thermocouple with a diameter of $1.5 \mathrm{~mm}$ and an accuracy of $2.2 \mathrm{~K}$. The combustion exhaust was discharged from the combustor by a force-ventilated extractor hood during the measurements.

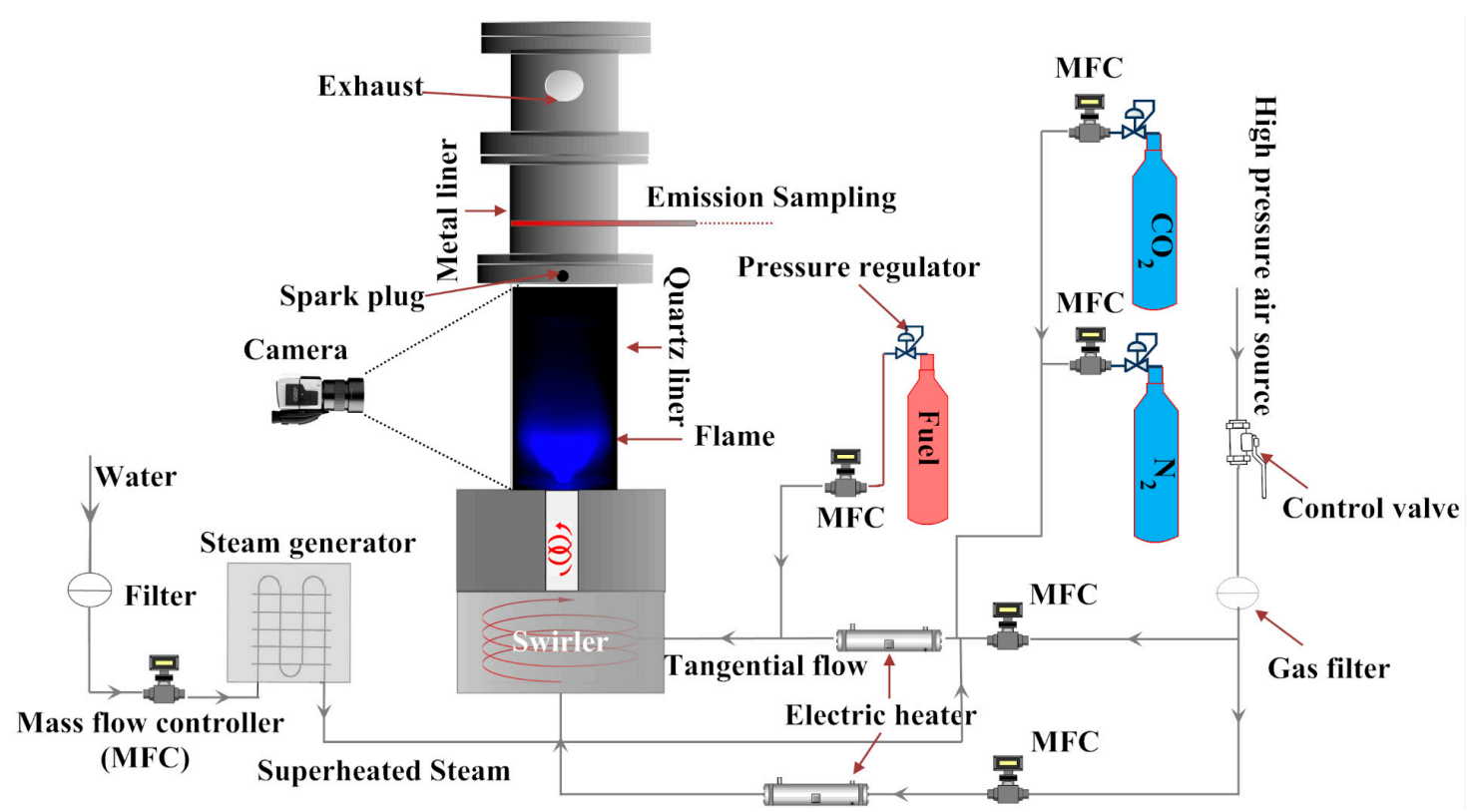

Figure 1. Experimental test facility.

Figure 2 depicts the gas turbine model combustor that is mounted on a pneumatic actuator system. The cylindrical combustor has an overall length of $350 \mathrm{~mm}$ and consists of two sections. The upper section is made of metal and the lower section is a quartz liner with $120 \mathrm{~mm}$ length, which makes it possible for flame visualization and optical measurements. The flow from the axial and tangential direction was mixed in the swirler that is mounted at the upstream location of the combustor inlet. Prior to the swirler, a sintered flow straightener with an average porosity of $200 \mu \mathrm{m}$ was used to generate a more homogeneous velocity for the flow from the axial direction. Four channels with $3 \mathrm{~mm}$ wide and $10 \mathrm{~mm}$ high were designed for the entering of the flow from tangential direction. The proportions of the flow from axial and tangential direction are adjustable so that the swirl number used in the experiments can be altered. In order to illustrate the swirl strength, the nondimensional swirl number is defined:

$$
S=\frac{G_{r}}{R G_{a}}
$$


where $S$ represents the swirl number, $G_{r}$ denotes the axial flux of the radial momentum, $R$ is the radius of the swirler, and $G_{a}$ is the axial flux of the axial momentum. $G_{r}$ and $G_{a}$ in the above equation can be calculated as:

$$
\begin{aligned}
& G_{r}=2 \pi \int_{0}^{R} \rho U V r^{2} d r \\
& G_{a}=2 \pi \int_{0}^{R} \rho U^{2} r d r
\end{aligned}
$$

where $\rho$ is the gas density, $U$ is the axial velocity, and $V$ is the radial velocity. For the purpose of determining the swirl number under different flow conditions, the axial and radial velocity profiles were measured with Laser Doppler Anemometry (LDA) in previous work, and a relationship between radial to axial momentum ratio and swirl number was established. It should be noted that distinctive flow field could be obtained with different swirl numbers.

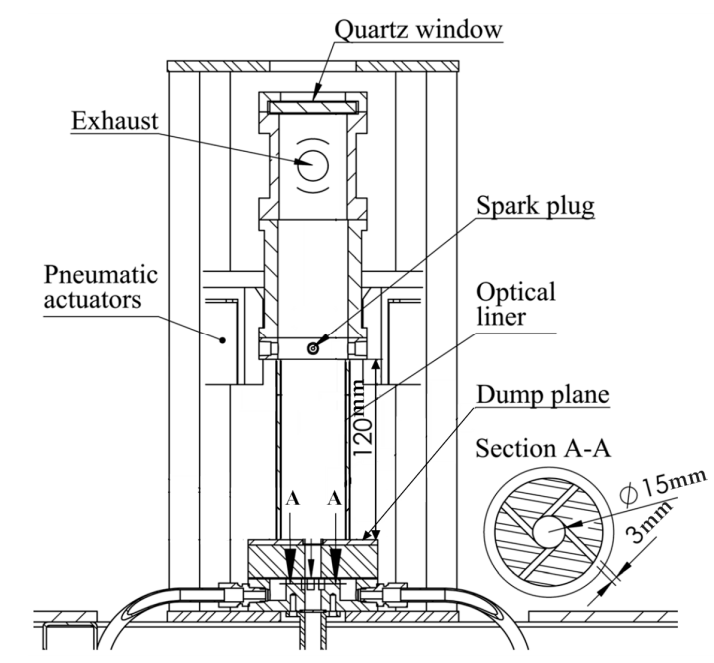

Figure 2. Swirl-stabilized combustor with optical access and swirler cross-section.

The main parameters of the experiments operation are shown in Table 1. The flame LBO limits were obtained by gradually decreasing the methane flow until the flame was physically away from the combustor. In order to avoid flame LBO due to the large sudden changes, the methane flow was reduced with the smallest step (equivalent to 0.00636 in equivalence ratio) allowed by the mass flow controller.

Table 1. Experimental Operating Conditions.

\begin{tabular}{cccc}
\hline Operation Parameter & Units & Title & Uncertainty \\
\hline Fuel & {$[-]$} & $\mathrm{CH}_{4}(99.98 \%)$ & {$[-]$} \\
Fuel flow rate & $(\mathrm{g} / \mathrm{s})$ & $0.075-0.175$ & \pm 0.002 \\
Air flow rate & $(\mathrm{g} / \mathrm{s})$ & $2.96-2.07$ & \pm 0.02 \\
Equivalence ratio & {$[-]$} & $1-\mathrm{LBO}$ limits & 0.01 \\
Swirl number & {$[-]$} & 0.58 & \pm 0.01 \\
Preheated temperature & $(\mathrm{K})$ & $384 / 484$ & \pm 2 \\
Vitiation species & {$[-]$} & $\mathrm{N}_{2} / \mathrm{CO}_{2} / \mathrm{H}_{2} \mathrm{O}$ & {$[-]$} \\
\hline
\end{tabular}

\subsection{Flame Visualization}

In order to study the vitiation effects on the flame shapes and anchored locations, the time-averaged $\mathrm{CH}$ chemiluminescence were captured by a CCD camera (D70s, Nikon, Tokyo, Japan) equipped with an AF Nikkor lens (50 mm/F1.8D, Nikon, Tokyo, Japan) and a band-pass $\mathrm{CH}$ filter (430/10, LaVision, Göttingen, Germany). An exposure time of $0.77 \mathrm{~s}$ and a resolution of $3008 \times 2000$ pixels were used in the measurements. The aperture was set into $\mathrm{f} / 1.8$ throughout all the 
experiments. A high-speed CMOS camera (Vision Research Phantom V611) was used to capture the broadband flame chemiluminescence. The fluctuation of the chemiluminescence intensity could be used to indicate the dynamics of the local heat-release. The recording frequency was $1 \mathrm{kHz}$ and the resolution is $1280 \times 800$ pixels.

\subsection{CO Emission Measurement}

The CO emission was measured by a Rosemount Binos 100 NDIR (nondispersive infrared photometers) $\mathrm{CO} / \mathrm{CO}_{2}$ gas analyzer with a measurement uncertainty of $5 \mathrm{ppm}$. The exhaust gas sample was collected by a water-cooled probe which is mounted at the exit of the combustor. The average sampling of the exhaust gas was ensured by the multiple holes on the emission probe. Prior to the emission analyzer, an exhaust gas cooler was used to avoid the condensing of the steam contained in the collected sample gas. In order to reduce the errors of emission analysis, the emission analyzers were calibrated every time prior to the experiments with standard calibration gases.

\subsection{Chemical Calculation}

In order to understand the vitiation effects on the chemical reactions in the flame reaction zone, chemical kinetics calculation was involved in present work. The calculation was carried out with the usage of Chemkin-Pro software package and the GRI-Mech 3.0 mechanism. An equilibrium reactor was used for the adiabatic flame temperature calculation for a wide range of equivalence ratios. The flame reaction zone was modeled by a premixed laminar flame speed calculation reactor [17], based on which the important changes in species concentration, temperature, etc., can be observed.

\section{Results and Discussion}

The premixed turbulent combustion is a complex process which is determined by many factors, e.g., chemical reactions, turbulent flow, and heat and mass transfer. Therefore, the flame stability and emission performance strongly depend on these factors and the interactions among them. In the case of using reactant stream with different composition, the variation in physical properties and the chemical kinetics probably lead to new characteristics in combustion progress. In order to study the characteristics of vitiated methane flame, $10 \%, 20 \%$, and $30 \%$ mole fraction of the air was substituted by $\mathrm{N}_{2}, \mathrm{CO}_{2}$, and steam, respectively. The mole fraction of vitiation gas was defined as the vitiation ratio which was used in the results analysis.

\subsection{Reaction Zone Characteristics}

In the premixed combustion, most of the chemical reactions occur in a narrow zone which is referred to as the reaction zone. The reaction zone separates the unburned reactant mixtures and the combustion products. Significant changes in temperature, combustion intermediate radicals, fuel, oxidizer, etc., are observed across the reaction zone. Figure 3 shows the comparison of temperature profile across the flame reaction zone at equivalence ratio 0.8 and the vitiation effects on the adiabatic flame temperature at the equivalence ratio range of 0.3 to 1 . The results were calculated, respectively, with a premixed laminar flame speed calculation reactor and equilibrium reactor in Chemkin software. Based on Figure 3a, a reduction in temperature gradient was observed with $20 \%$ vitiation gas, which indicated a decrease in chemical reaction rate. In Figure $3 b$, as a result of the changes in chemical and physical properties of the reactant mixtures, the final adiabatic flame temperature of vitiated flame had a significant decrease compared to the flame without vitiation. Among the three vitiation gas, combustion with $20 \% \mathrm{CO}_{2}$ had the minimum flame temperature. This was probably due to its specific heat capacity and the inhibiting effect on $\mathrm{CO}$ oxidization. 

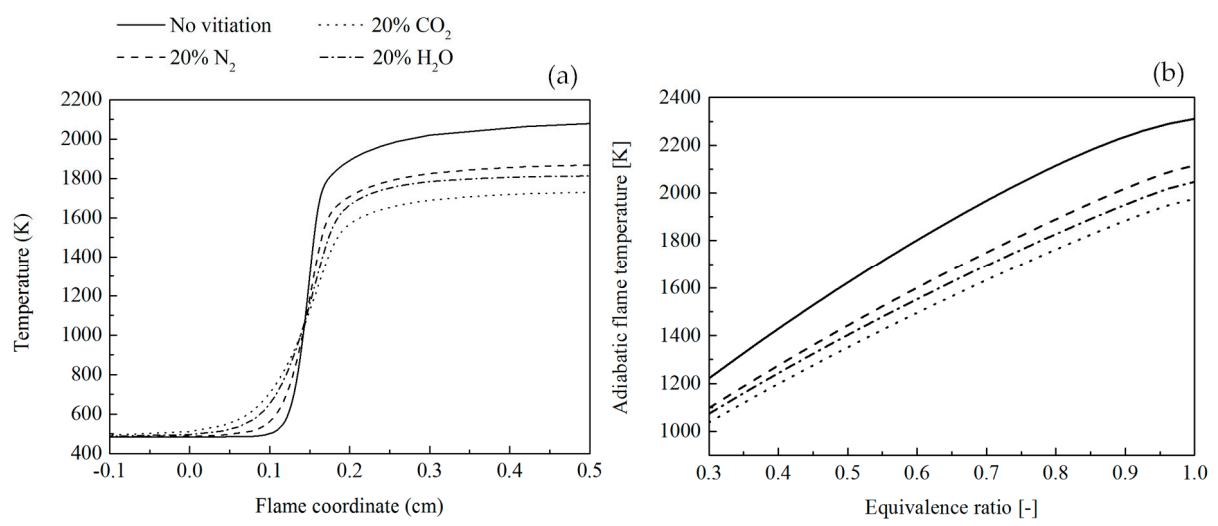

Figure 3. The vitiation effects on (a) the flame temperature profile in the flame reaction zone at equivalence ratio $=0.8$ and $(\mathbf{b})$ the adiabatic flame temperature with $20 \%$ vitiation ratio at combustor inlet temperature of $484 \mathrm{~K}$.

Figure 4 shows the concentration of $\mathrm{H}, \mathrm{O}, \mathrm{OH}$, and $\mathrm{CO}$ across the flame reaction zone. A comparison of the concentration of these species has been made for the vitiated flame and flame without vitiation. The data were calculated with the premixed laminar flame speed calculation reactor in Chemkin software. Based on the data, there was a great concentration gradient between the unburned reactant mixtures and the reaction zone. Compared to the flame with no vitiation, the concentration of $\mathrm{H}, \mathrm{O}, \mathrm{OH}$, and $\mathrm{CO}$ of the vitiated flame decreased significantly. With $20 \%$ vitiation ratio, the reduction in species concentration was expected because the amount of the active radicals was less due to the fact that less oxygen was available for the chemical reactions. If only the dilution effect of the vitiation plays a role in the chemical reactions, the concentration of the same species shown in Figure 4 should stay the same regardless of the type of vitiation. However, the data in Figure 4 clearly shows that the concentration of $\mathrm{H}, \mathrm{O}, \mathrm{OH}$, and $\mathrm{CO}$ strongly depends on the type of the vitiation. This means, besides the vitiation dilution effect, the vitiation species can influence the combustion reaction process in a more complicated way due to the different chemical properties, physical properties, and the interaction between them.
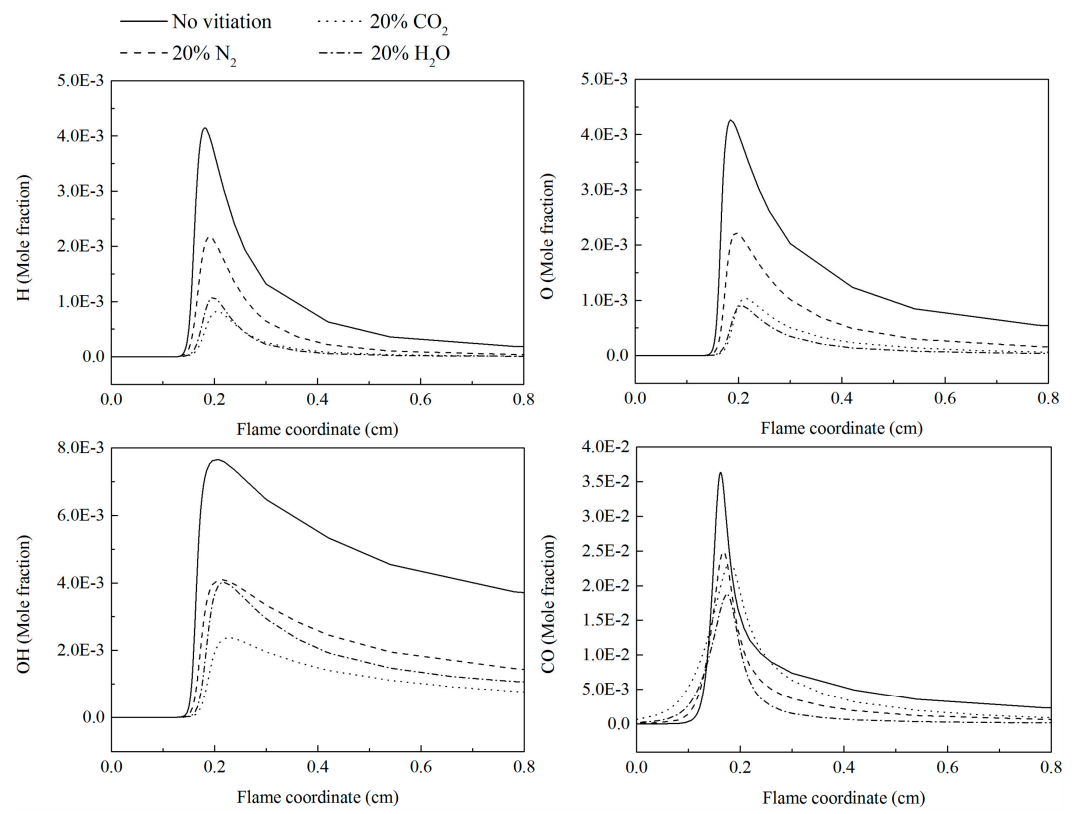

Figure 4. Comparison of intermediate radicals and CO in the flame reaction zone at $20 \%$ vitiation ratio, equivalence ratio $=0.8$ and combustor inlet temperature of $484 \mathrm{~K}$. 
By comparing the species concentration with the vitiation of $\mathrm{N}_{2}, \mathrm{CO}_{2}$, and $\mathrm{H}_{2} \mathrm{O}, \mathrm{N}_{2}$ was found to have minimum changes in active radical concentration. In other words, $\mathrm{N}_{2}$ had a minimum influence on combustion process among the three vitiation gas. The primary reason could be that the adiabatic flame temperature with $\mathrm{N}_{2}$ is higher than that with $\mathrm{CO}_{2}$ and $\mathrm{H}_{2} \mathrm{O}$. As a result, the reaction rate is enhanced and the radical concentration is higher. In the flame reaction zone, the $\mathrm{CO}_{2}$ and $\mathrm{H}_{2} \mathrm{O}$ had a close peak concentration for $\mathrm{H}$ radical. A similar performance for $\mathrm{O}$ radical was observed with the vitiation of $\mathrm{CO}_{2}$ and $\mathrm{H}_{2} \mathrm{O}$. With $\mathrm{N}_{2}$ vitiation gas, the peak concentration of $\mathrm{H}$ and $\mathrm{O}$ radicals was about double that with $\mathrm{CO}_{2}$ and $\mathrm{H}_{2} \mathrm{O}$. According to the $\mathrm{OH}$ concentration profile across the reaction zone, it was observed that the $\mathrm{H}_{2} \mathrm{O}$ and $\mathrm{N}_{2}$ vitiation gas had almost the same peak concentration, although the adiabatic flame temperature with $\mathrm{H}_{2} \mathrm{O}$ vitiation gas was lower. This can be explained by the results of the previous research work, which indicated that more $\mathrm{OH}$ radicals were produced based on the chemical reaction step $\mathrm{O}+\mathrm{H}_{2} \mathrm{O} \rightarrow \mathrm{OH}+\mathrm{OH}[8,9]$. At high flame temperature, the steam dissociation could also contribute to $\mathrm{OH}$ production [10]. The flame vitiated with $\mathrm{CO}_{2}$ had the lowest adiabatic flame temperature according to the data in Figure 3. However, it showed a $\mathrm{CO}$ peak concentration which was comparable to flame with $\mathrm{N}_{2}$ vitiation. Studies have shown that the $\mathrm{CO}$ oxidation is primarily determined by the reaction step $\mathrm{CO}+\mathrm{OH} \rightarrow \mathrm{CO}_{2}+\mathrm{H}$ [18]. Hence, the $20 \% \mathrm{CO}_{2}$ vitiation and lower concentration of $\mathrm{OH}$ could lead to a higher $\mathrm{CO}$ concentration in the flame reaction zone.

\subsection{Flame Visualization}

In the present measurement, the characteristics of vitiated flames were investigated with a swirl number of 0.58 , which can produce a center recirculation zone in the combustor, according to the previous particle image velocimetry (PIV) measurement. Time-averaged $\mathrm{CH}$ chemiluminescence was used to provide the information about the flame shapes, stabilized location, flame length, and so on. Figure 5 depicts the flame shape's response to the vitiation of $\mathrm{N}_{2}, \mathrm{CO}_{2}$, and $\mathrm{H}_{2} \mathrm{O}$ with $10 \%$ vitiation ratio. The high $\mathrm{CH}$ intensity area circled by the red dashed line could provide the indication for the main reaction zone. For the flame without vitiation, the $\mathrm{CH}$ intensity was stronger compared to the flame with vitiation. The $10 \% \mathrm{~N}_{2}$ did not make significant changes on flame shape, however-the $\mathrm{CH}$ intensity in the main reaction zone was lower. It can be seen from Figure 5 that $\mathrm{CO}_{2}$ and $\mathrm{H}_{2} \mathrm{O}$ had an observable influence on the flame height and the location of the main reaction zone. With $10 \%$ $\mathrm{CO}_{2}$, the flame height was increased and the flame root had a tendency to detach from the edge of the combustor inlet. The lower $\mathrm{CH}$ intensity in the main reaction zone showed $\mathrm{CO}_{2}$ had a stronger inhibiting effect on the chemical reaction than $\mathrm{N}_{2}$. This is probably due to the relatively larger heat capacity of $\mathrm{CO}_{2}$ and its negative effect on $\mathrm{CO}$ oxidization. The $\mathrm{H}_{2} \mathrm{O}$ seemed to have the maximal reduction in $\mathrm{CH}$ intensity; at the same time, there was a small lift-off height between the flame root and the combustor inlet. This indicated that the chemical reaction rate was decreased greatly by $\mathrm{H}_{2} \mathrm{O}$. This could be due to the high emissivity of steam, which leads to a remarkable heat loss. 


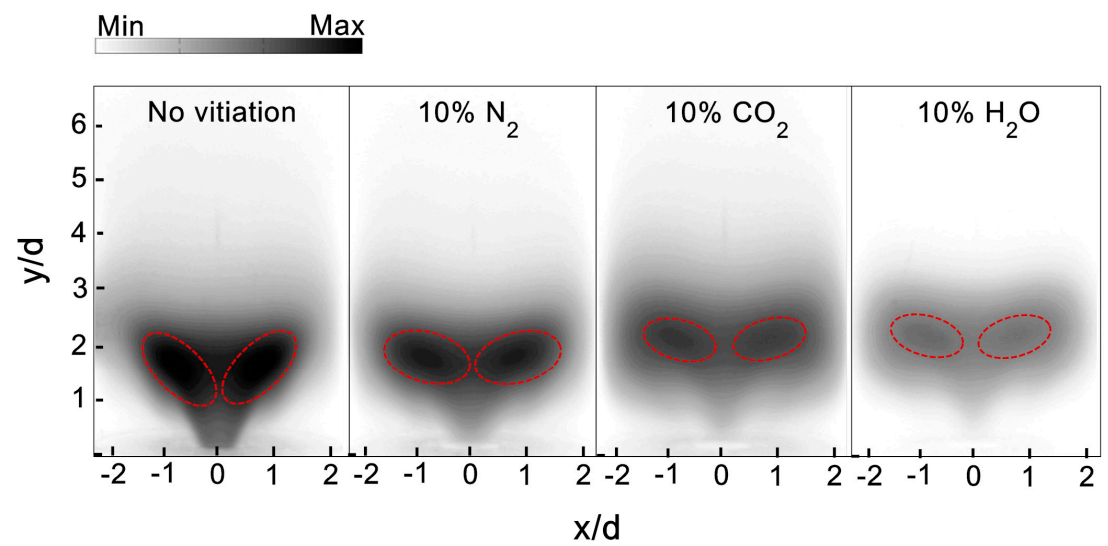

Figure 5. Time-averaged $\mathrm{CH}$ chemiluminescence shows the vitiated flames with vitiation ratio $=10 \%$ and equivalence ratio $=0.89$.

Figure 6 illustrates the comparison of flame shapes for the three vitiation species at the vitiation ratio of $10 \%$ and $20 \%$. At the equivalence ratio of 0.98 , with the increase of vitiation ratio from $10 \%$ to $20 \%$, a substantial reduction of $\mathrm{CH}$ intensity was observed for $\mathrm{N}_{2}, \mathrm{CO}_{2}$, and $\mathrm{H}_{2} \mathrm{O}$. For $\mathrm{N}_{2}$, the $\mathrm{CH}$ images showed that the flame stabilized position was slightly shifted downstream. With $20 \% \mathrm{CO}_{2}$, four stabilized positions of flame were achieved. Two of the stabilized positions were shifted downstream, compared to $10 \% \mathrm{CO}_{2}$ case. The other two were located upstream at the combustor corner. A minimal $\mathrm{CH}$ intensity was observed in flame with $20 \%$ steam vitiation. Even at the main reaction zone, a much stronger chemical reaction rate was still not observed. Therefore, it could be expected that the flame with $20 \%$ steam has a weak flame stabilization ability compared with the other vitiated flames.

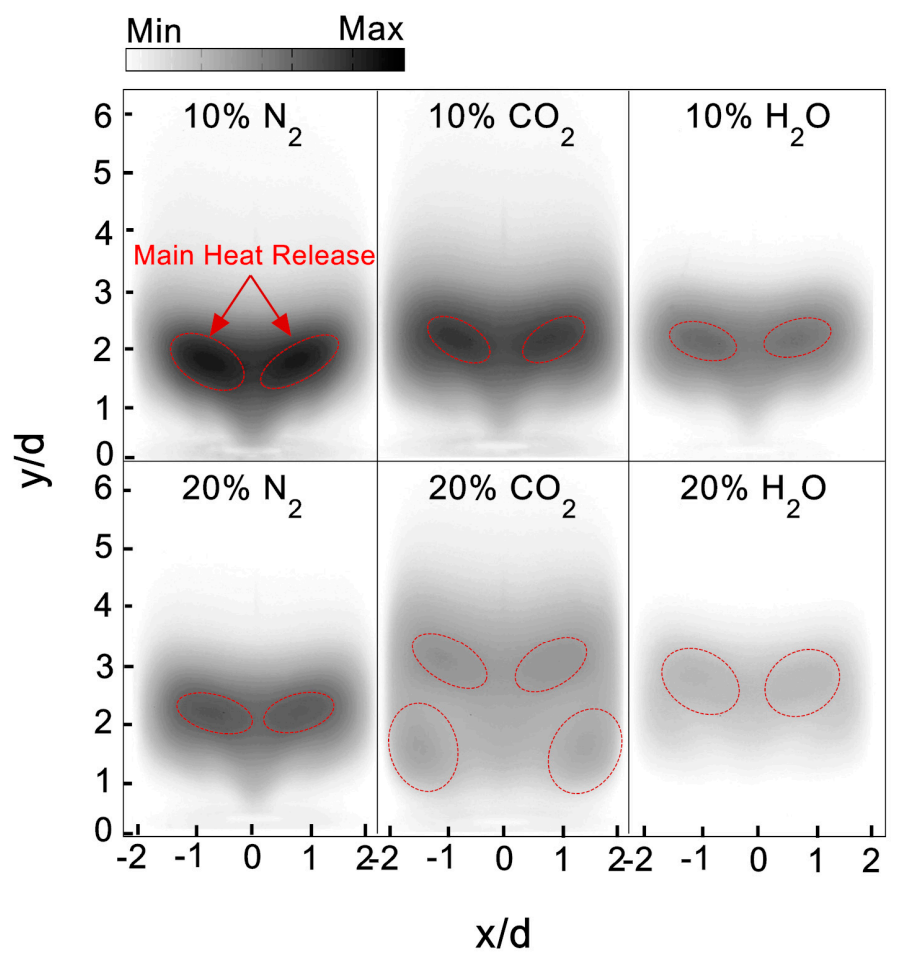

Figure 6. Time-averaged $\mathrm{CH}$ chemiluminescence shows the vitiation ratio effects on vitiated flames, equivalence ratio $=0.98$. 


\subsection{The LBO of Vitiated Flame}

The flame LBO should be avoided in practice combustor operation. Hence, it is essential to know the LBO limits in order to have an economical and safe operation. The LBO limits, defined as the LBO equivalence ratio, were determined by gradually reducing the fuel until the flame was physically away from the combustor. LBO limits were measured for the premixed methane flame with vitiation of $\mathrm{N}_{2}$, $\mathrm{CO}_{2}$, and $\mathrm{H}_{2} \mathrm{O} .10 \%, 20 \%$, and $30 \%$ vitiation ratio were examined at combustor inlet temperature of $484 \mathrm{~K}$. Figure 7 a shows the vitiation effect on the LBO limits. For all the vitiation species, the LBO limits went up with the increase of vitiation ratio. It was found that the LBO limits with the vitiation of $\mathrm{CO}_{2}$ and $\mathrm{H}_{2} \mathrm{O}$ had a similar trend which was highlighted by the shadow region. Compared to the flame vitiated by $\mathrm{CO}_{2}$ and $\mathrm{H}_{2} \mathrm{O}$, the vitiation ratio had a relatively small influence on flame vitiated by $\mathrm{N}_{2}$. The reason for the LBO limits trend in Figure 7a could be understood based on the discussion in Section 3.1, where the vitiation effects on the flame reaction zone were analyzed. In Figure 7b, the LBO limits were analyzed based on the Damköhler number at the LBO condition. The Damköhler number was defined as:

$$
D a=\tau_{\text {res }} / \tau_{\text {chem }}
$$

which is a time scale ratio between the residence time and the chemical reaction time. Regarding the calculation method for the Damköhler number, the readers are suggested to refer to the previous work [14].
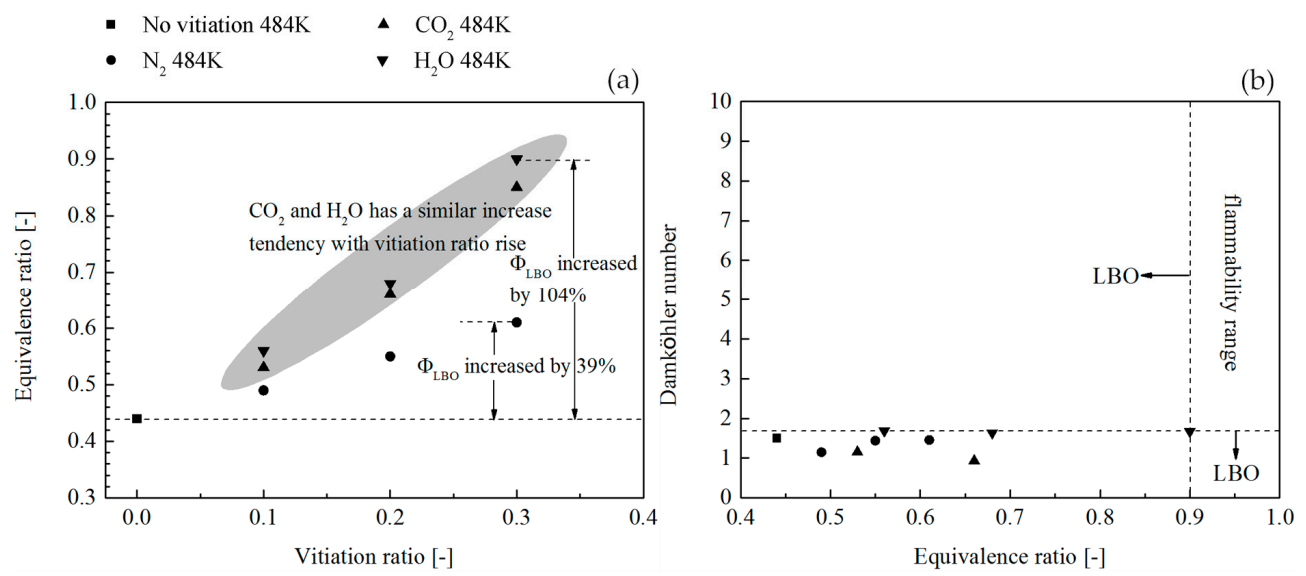

Figure 7. The influence of vitiation on (a) combustion Lean Blowout (LBO) limits and (b) the flammability boundaries of Damköhler number and equivalence ratio, at $484 \mathrm{~K}$ combustor inlet temperature.

The dashed line in Figure $7 \mathrm{~b}$ shows a two-dimensional flammability range, which is controlled by the equivalence ratio flammability limit and the Damköhler number flammability limit. Above the equivalence ratio flammability limit, a sufficiently high temperature is guaranteed to keep the combustion reaction rate (in other words, to keep the flame propagation). However, although the flame can propagate towards the unburned premixed reactant mixtures, the propagation speed may be lower than the flow speed, which will lead to the combustion LBO. Based on a time concept, it is to say an adequate time must be ensured to complete the chemical reaction in order to avoid LBO. Therefore, it is important to know the critical Damköhler number limit above which the flame can survive in the combustor. According to Figure $7 \mathrm{~b}$, the changes of vitiation species and vitiation ratio did not have a significant influence on the Damköhler number flammability limit.

Figure 8a shows the comparison of LBO limits between combustor inlet temperature of $384 \mathrm{~K}$ and $484 \mathrm{~K}$ with $10 \%$ vitiation ratio. The results indicated that the higher combustor inlet temperature could extend the LBO limits to the lower level. Figure $8 \mathrm{~b}$ shows the adiabatic flame temperature at the LBO limits. The vitiation ratio influence on the adiabatic flame temperature was examined with 
$484 \mathrm{~K}$ combustor inlet temperature. The results indicated that higher vitiation ratio could lead to an increase of the adiabatic flame temperature at LBO. The data marked with the dashed line shows the comparison between $484 \mathrm{~K}$ and $384 \mathrm{~K}$. According to the results, the inlet temperature influence on the adiabatic flame temperature at LBO is very little.
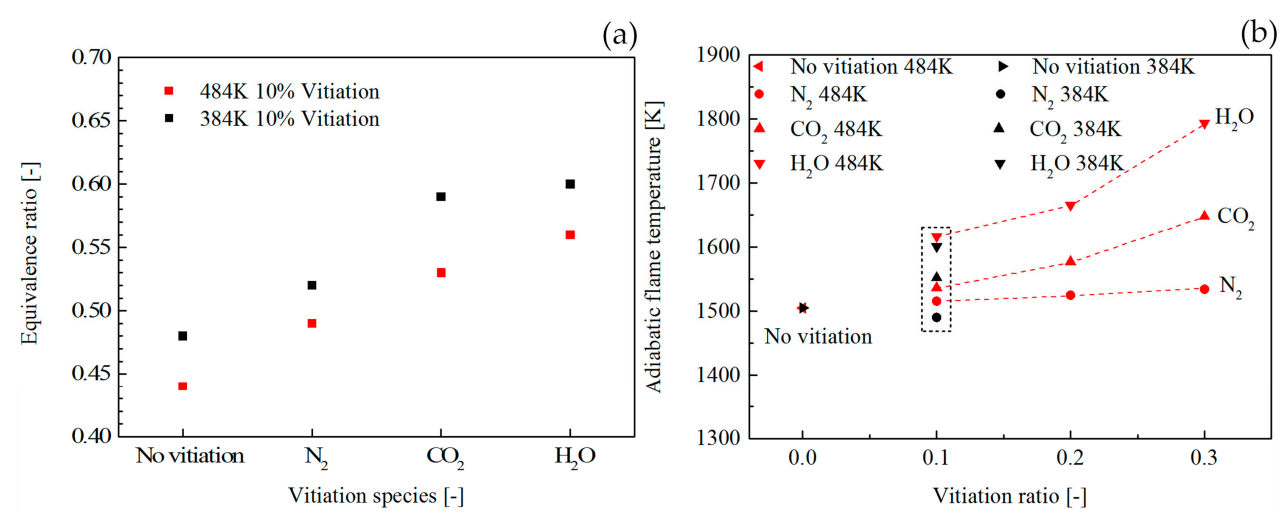

Figure 8. The combustor inlet temperature influence on (a) LBO limits of vitiated flame and (b) the dependence of the Adiabatic flame temperature on vitiation ratio.

In the vicinity of LBO limits, the flame reaction zone can be very sensitive to the heat loss from the flame, the fluctuation of the high strain rate, and the local equivalence ratio. Therefore, the local flame extinction and flame re-ignition process can happen [19]. The local flame extinction can detach the flame from its stabilized location and the flame re-ignition process can make the flame propagate back to the previously stabilized place again. This flame instability behavior sometimes can stop the flame re-ignition and attachment process, which finally leads to the LBO. Figure 9 shows the flame re-ignition and detachment phenomena which were recorded by the high-speed chemiluminescence imaging at a frequency of $1 \mathrm{kHz}$. Due to the usage of swirling flow, the flame had a rotating movement along the combustor center line besides the flame movements in the vertical direction. At $0 \mathrm{~ms}$, it was observed that the flame stayed away from the dump plane of the combustor. Later, the flame re-ignition and attachment process were observed, which made the flame travel upstream (from $2 \mathrm{~ms}$ to $6 \mathrm{~ms}$ ). The flame was found in the outer recirculation zone for a short time interval (from the time $7 \mathrm{~ms}$ to $12 \mathrm{~ms}$ ). Then, the flame detachment was found, which made the flame travel downstream along the combustor liner. In the end, a complete flame detachment from the dump plane and the outer recirculation zone was achieved. The described flame unstable phenomena can be observed in all the examined flame cases when approaching the LBO limits.

According to the previous literature, the flame chemiluminescence is correlated with time-dependent variation of heat-release rate [20]. Therefore, the dynamics of high-speed chemiluminescence are very helpful for providing the information of heat-release rate fluctuation, which is essentially produced by the coupling of fluctuation between the heat-release and the pressure. The high-speed chemiluminescence was recorded in time sequence. The spatial average of intensity was calculated for each image and the time-dependent fluctuation of the average intensity was analyzed by FFT (Fast Fourier Transform). Figure 10 illustrates the FFT analysis result, which shows the frequency peaks for the chemiluminescence intensity oscillation observed in the proximity of LBO. Results showed that the dominant frequency of intensity fluctuation was not affected significantly by the $10 \%$ vitiation gas. 


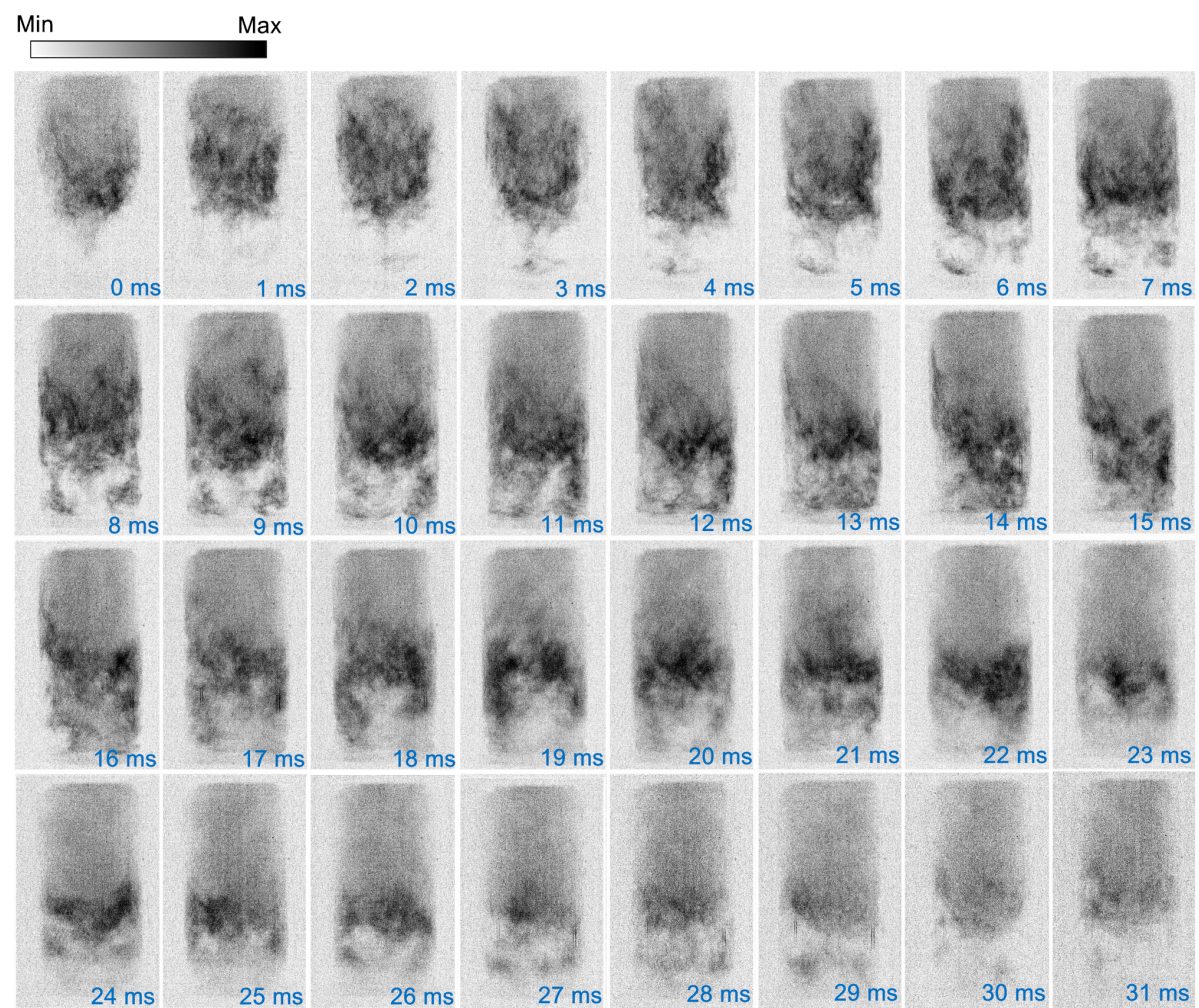

Figure 9. The high-speed broadband chemiluminescence images in time sequence, which show the flame re-ignition and detachment process without vitiation. Equivalence ratio is 0.5 and combustor inlet temperature is $484 \mathrm{~K}$.

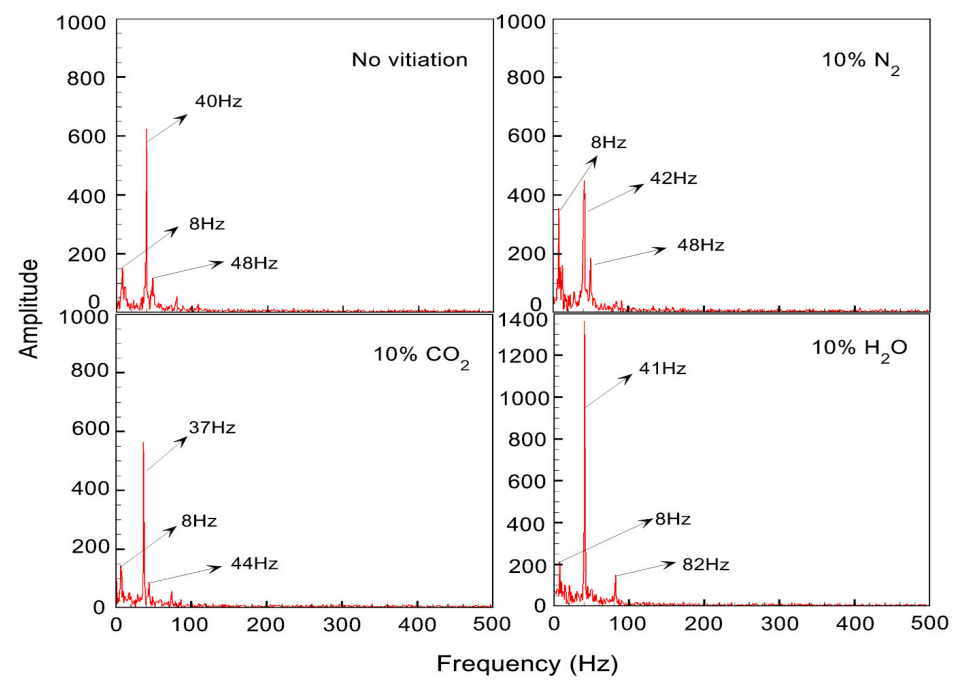

Figure 10. Comparison of Fast Fourier Transfer (FFT) analysis results for the vitiation effects on the heat-release dynamics at the condition close to the LBO limits.

\subsection{The Vitiation Effects on CO Emission}

In this section, the $\mathrm{CO}$ emission performance of vitiated flames was examined with three vitiation ratios and two combustor inlet temperatures. Figure 11 shows a comparison of $\mathrm{CO}$ concentration in the combustion products between the flame without vitiation and the flame with $10 \%$ vitiation ratio. In order to compare the vitiation effect on $\mathrm{CO}$ emission, a concentration limit was defined at $25 \mathrm{ppm}$ 
below which the $\mathrm{CO}$ is considered acceptable. Figure 11a shows that the combustion operated in a very lean condition leads to a high CO concentration in the combustion products. This is due to the low flame temperature, which can reduce the chemical reaction rate for $\mathrm{CO}$ oxidation. The equivalence ratios where $\mathrm{CO}$ equals to $25 \mathrm{ppm}$ are denoted by $\mathrm{L}_{1}, \mathrm{~L}_{2}, \mathrm{~L}_{3}$, and $\mathrm{L}_{4}$, and the subscript stands for the corresponding flame case. Figure $11 \mathrm{~b}$ shows the equivalence ratio range from 0.65 to 0.85 , where the $\mathrm{CO}$ of all flames is smaller than $25 \mathrm{ppm}$. In this range, the flame temperature was increased and the $\mathrm{CO}$ oxidation rate was improved; therefore, the $\mathrm{CO}$ concentration was reduced. It was observed that the flame with $10 \% \mathrm{CO}_{2}$ vitiation basically had the same $\mathrm{CO}$ performance compared to the flame without vitiation. The $\mathrm{CO}$ behavior with $\mathrm{CO}_{2}$ vitiation could be understood from the two contrary effects on the $\mathrm{CO}$ emission. One is the inhibiting effect on $\mathrm{CO}$ formation which has been indicated by many studies. The other one is the flame temperature reduction effect which weakens the dissociation from $\mathrm{CO}_{2}$ to $\mathrm{CO}$. In the end, the $\mathrm{CO}$ concentration is determined by the joint effects of the two contrary effects. With $10 \% \mathrm{~N}_{2}$ and $10 \% \mathrm{H}_{2} \mathrm{O}$ vitiation, a more and more obvious $\mathrm{CO}$ reduction effect was found as the increase of equivalence ratio. This was probably because the adiabatic flame temperature is low, hence the $\mathrm{CO}_{2}$ dissociation is not strong. Figure 11c shows the $\mathrm{CO}$ profile when approaching stoichiometric condition; the dissociation of $\mathrm{CO}_{2}$ plays a more important role and yields an increase of $\mathrm{CO}$ concentration. The equivalence ratios where $\mathrm{CO}$ equals to $25 \mathrm{ppm}$ are denoted by $\mathrm{H}_{1}, \mathrm{H}_{2}, \mathrm{H}_{3}$, and $\mathrm{H}_{4}$.
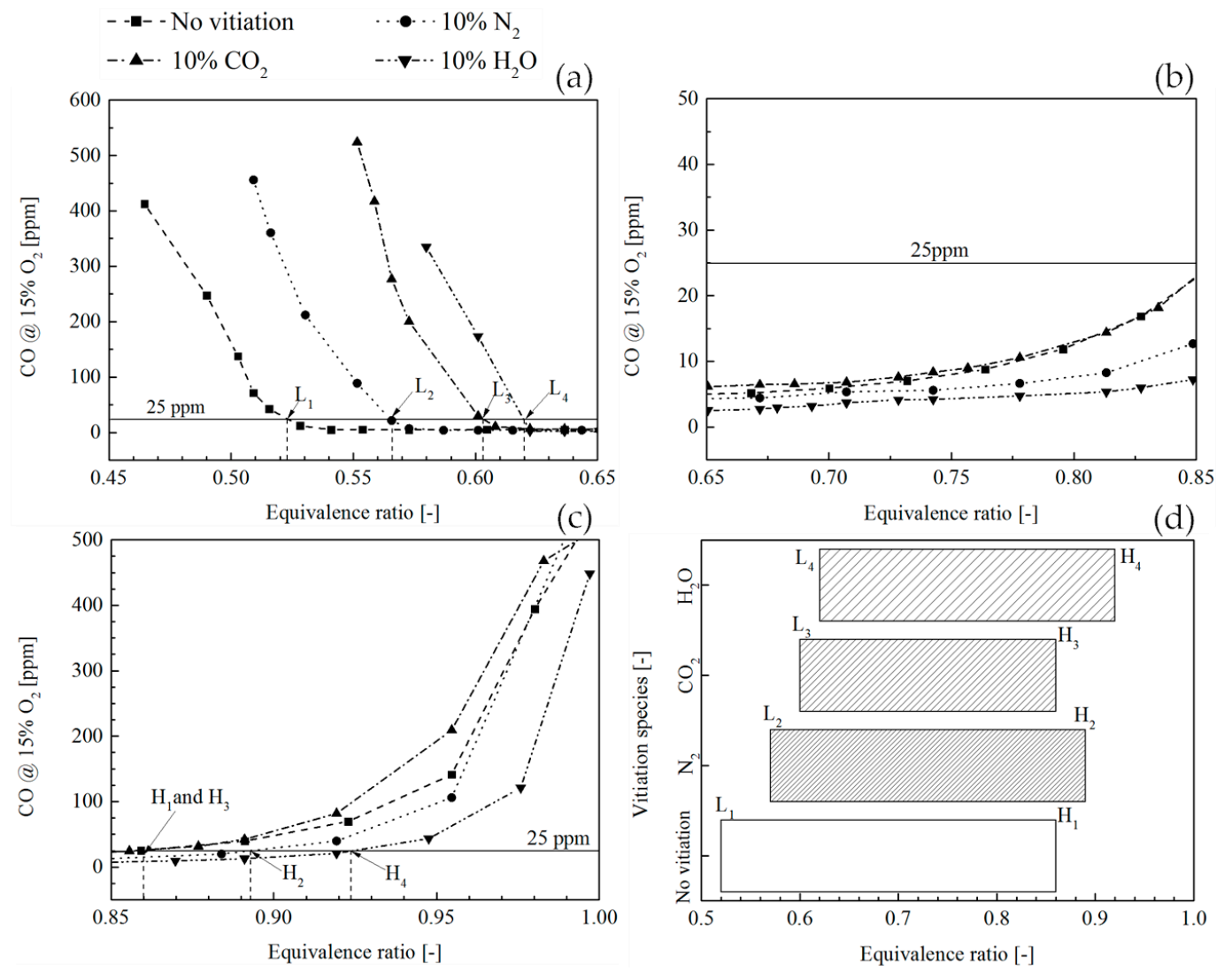

Figure 11. The effects of three types vitiation on $\mathrm{CO}$ emission performance along the equivalence ratio range of (a) 0.45 to 0.65 ; (b) 0.65 to 0.85 ; and (c) 0.85 to 1.00 ; (d) shows the comparison of equivalence ratio range for low $\mathrm{CO}$ operation with the $484 \mathrm{~K}$ combustor inlet temperature and $10 \%$ vitiation ratio.

Figure 11a-c shows the $\mathrm{CO}$ concentration trend along the increase of equivalence ratio. The operation with $\mathrm{CO}$ lower than $25 \mathrm{ppm}$ was only possible between the two equivalence ratio limits which are shown in Figure 11d. It was found that the $10 \%$ vitiation gas led to a smaller 
equivalence ratio range for $\mathrm{CO}$ lower than $25 \mathrm{ppm}$. Among the three vitiation species, $\mathrm{CO}_{2}$ had the most significant effects on low $\mathrm{CO}$ operation.

Figure $12(\mathrm{a} 1, \mathrm{~b} 1, \mathrm{c} 1)$ shows a comparison of $\mathrm{CO}$ profile with the vitiation ratio of $10 \%, 20 \%$, and $30 \%$. Figure $12(\mathrm{a} 2, \mathrm{~b} 2, \mathrm{c} 2)$ shows the dependency of $\mathrm{CO}$ on the adiabatic flame temperature. As the increase of vitiation ratio, the flame temperature was decreased. Therefore, at the LBO side, the CO rise due to the low flame temperature shifted to higher equivalence ratios. This tendency has been presented in Figure 12(a1,b1,c1). At the side where the equivalence ratio was close to 1, the CO rise was found in all the flames. A common phenomenon was that the higher vitiation ratio made the location where $\mathrm{CO}$ had a rapid rise shift to lower adiabatic flame temperatures. This was the result of the joint effects of the $\mathrm{CO}$ oxidation rate and the $\mathrm{CO}_{2}$ dissociation rate. When the $\mathrm{CO}_{2}$ dissociation rate was stronger than the $\mathrm{CO}$ oxidation rate due to the dilution effects of the vitiation, the $\mathrm{CO}$ concentration was increased even the flame temperature is not high.
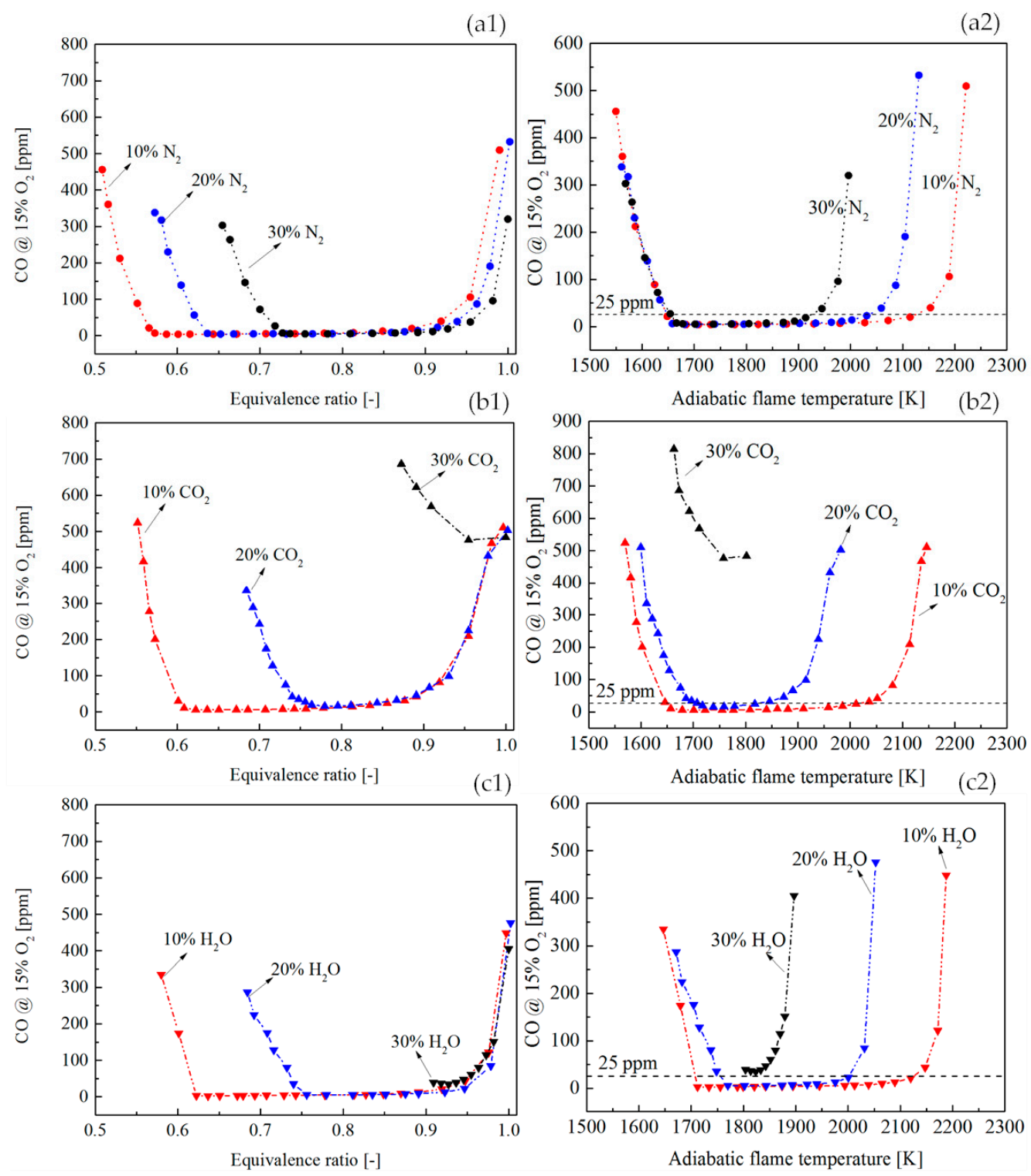

Figure 12. Vitiation ratio effects on $\mathrm{CO}$ emission with combustor inlet temperature of $484 \mathrm{~K} .(\mathbf{a 1}, \mathbf{a 2})$ shows the $\mathrm{N}_{2}$ effects; (b1,b2) shows the $\mathrm{CO}_{2}$ effects; (c1,c2) shows the $\mathrm{H}_{2} \mathrm{O}$ effects.

Figure $12(\mathrm{a} 2, \mathrm{~b} 2, \mathrm{c} 2)$ shows that there was a limit of vitiation ratio, above which the $\mathrm{CO}$ was never below 25 ppm (even the temperature was still high). This is because the CO oxidation rate is not only 
determined by flame temperature but also by the reactant concentration. A very high vitiation ratio could lead to a reaction rate which is not sufficiently fast to complete the $\mathrm{CO}$ reaction in a limited residence time in the combustor. The vitiation ratio limit was proven to be determined by the vitiation species by the current results in Figure 12(a2,b2,c2). It could be observed that the vitiation limit of $\mathrm{N}_{2}$ was larger than $30 \%$. However, for $\mathrm{CO}_{2}$ and $\mathrm{H}_{2} \mathrm{O}$, their vitiation limits were below $30 \%$.

Figure $13(\mathrm{a} 1, \mathrm{~b} 1, \mathrm{c} 1)$ shows the $\mathrm{CO}$ profile in a scale range from 0 to $50 \mathrm{ppm}$, so that the vitiation effects can be observed when $\mathrm{CO}$ was low. Comparing the vitiation of $\mathrm{N}_{2}, \mathrm{CO}_{2}$, and $\mathrm{H}_{2} \mathrm{O}$, a reduction of equivalence ratio range was found for $\mathrm{CO}$ emission below $25 \mathrm{ppm}$, as the increase of vitiation ratio. With $30 \%$ vitiation, $\mathrm{CO}$ was never below $25 \mathrm{ppm}$ for the vitiation of $\mathrm{CO}_{2}$ and $\mathrm{H}_{2} \mathrm{O}$. The adiabatic flame temperature range for the CO below 25 ppm is shown in Figure 13(a2,b2,c2). The results indicated that the increase of vitiation ratio resulted in a smaller temperature region for low $\mathrm{CO}$ operation.
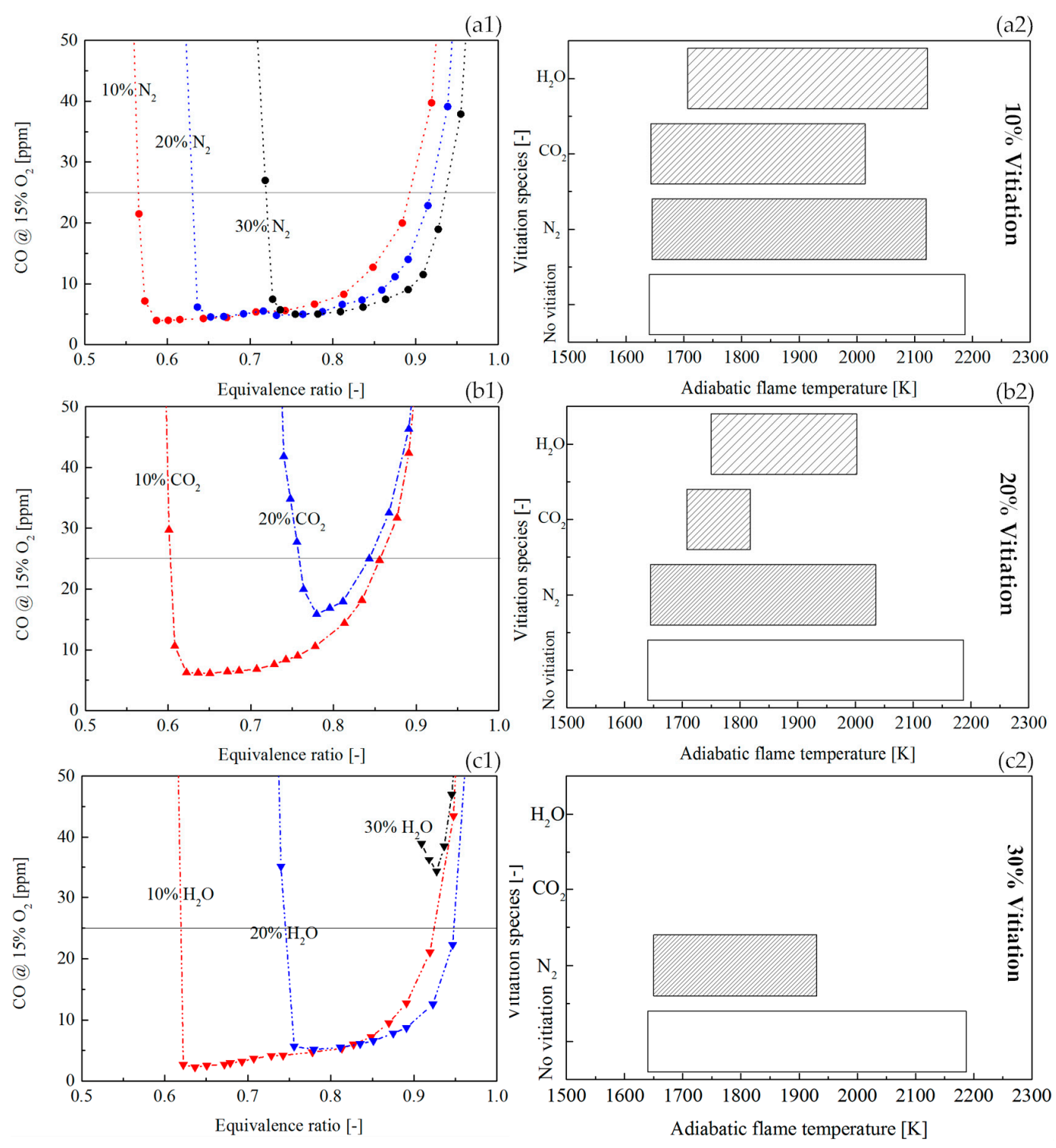

Figure 13. The equivalence ratio range under the vitiation of (a1) $\mathrm{N}_{2},(\mathbf{b} 1) \mathrm{CO}_{2},(\mathbf{c} 1) \mathrm{H}_{2} \mathrm{O}$, and the corresponding adiabatic flame temperature range with the vitiation ratio of (a2) $10 \%$, (b2) $20 \%$, (c2) $30 \%$, for low $\mathrm{CO}$ emission operation at combustor inlet temperature of $484 \mathrm{~K}$. 


\section{Conclusions}

An experimental investigation was performed on a premixed and swirl-stabilized gas turbine model combustor at atmospheric pressure. The characteristics of the vitiated methane combustion have been demonstrated. $10 \%, 20 \%$, and $30 \%$ mole fraction of the air were substituted by $\mathrm{N}_{2}, \mathrm{CO}_{2}$, and steam, respectively. The vitiation effects on the flame shapes, anchored location, LBO limits, and $\mathrm{CO}$ emission were studied experimentally. The measurement techniques, such as time-averaged $\mathrm{CH}$ chemiluminescence, high-speed broadband chemiluminescence, and $\mathrm{CO}$ emission monitoring were employed to characterize the features of the vitiated flame. Due to the variation of physical and chemical properties of the reactant mixtures, the chemical kinetics calculation was conducted to investigate vitiation effects on the flame reaction zone. Based on the analysis of the experimental and chemical kinetics calculation results, the below conclusions can be summarized as:

1. The chemical kinetics calculation showed a clear discrepancy of the flame reaction zone between the flame without vitiation and the vitiated flame. The calculation results revealed that across the flame reaction zone, the temperature gradient, the concentration of radicals $(\mathrm{H}, \mathrm{O}$, and $\mathrm{OH})$, and $\mathrm{CO}$ emission were decreased by the vitiation. A reduction in adiabatic flame temperature was also found with the vitiation. Among the vitiation of $\mathrm{N}_{2}, \mathrm{CO}_{2}$, and $\mathrm{H}_{2} \mathrm{O}, \mathrm{N}_{2}$ had the minimum influence on the flame reaction zone.

2. The time-averaged $\mathrm{CH}$ chemiluminescence showed that both the flame shapes and anchored location were affected by the vitiation. The increase in vitiation ratio $(10 \%$ to $30 \%)$ could lead to the alteration of flame shapes and the reduction of $\mathrm{CH}$ intensity. Among the three types of vitiation, $\mathrm{H}_{2} \mathrm{O}$ was found to have the maximum influence, the next was $\mathrm{CO}_{2}$, and the $\mathrm{N}_{2}$ had the minimum influence.

3. LBO limits and flammability boundaries of the Damköhler number were identified. Measurements results showed that the LBO limits were increased by the vitiation species; however, the increase could be compensated for by improving the combustor inlet temperature. With the vitiation of $\mathrm{CO}_{2}$ and $\mathrm{H}_{2} \mathrm{O}, \mathrm{LBO}$ limits had a similar increase tendency with the vitiation ratio rise between $10 \%$ and $30 \%$. However, for the flame vitiated by $\mathrm{N}_{2}$, the LBO limits increased at a slower rate. A significant influence on the Damköhler number flammability limit was not found with the changes of vitiation species and the vitiation ratio.

4. High-speed broadband chemiluminescence showed a common flame re-ignition and detachment process prior to the LBO limits. For this process, the time-dependent fluctuation of the average broadband intensity was analyzed by FFT and the results showed that flames vitiated by $\mathrm{N}_{2}$, $\mathrm{CO}_{2}$, and $\mathrm{H}_{2} \mathrm{O}$ had approximately the same peak frequency.

5. A reduction of the equivalence ratio range for low $\mathrm{CO}$ operation (below $25 \mathrm{ppm}$ ) was found in vitiated flames. Among the three vitiation species, $\mathrm{CO}_{2}$ has the most significant effects. It should be noticed that the $\mathrm{CO}$ concentration in the combustion products was determined by the joint impacts of flame temperature, reactant concentration, and vitiation species. Low CO operation was not possible with a sufficiently high vitiation ratio.

Overall, the present work provided an insight into the vitiated combustion. In the vitiated flames, the limit of the vitiation ratio existed below which a stable flame operation with low $\mathrm{CO}$ emission was possible, with a constant combustor inlet temperature.

Acknowledgments: The China Scholarship Council (CSC) has provided a great support for the authors Mao Li and Yiheng Tong. The authors acknowledge with the sincerest thanks.

Author Contributions: The experimental measurements and article writing were performed by Mao Li; experimental results were analyzed by Mao Li and Yiheng Tong; the paper proof-reading and revision were done by Marcus Thern and Jens Klingmann.

Conflicts of Interest: The authors declare no conflict of interest. 


\section{References}

1. Cavaliere, A.; de Joannon, M. Mild Combustion. Prog. Energy Combust. Sci. 2004, 30, 329-366. [CrossRef]

2. Le Cong, T.; Dagaut, P. Kinetics of natural gas, natural gas/syngas mixtures oxidation and effect of burnt gas recirculation: Experimental and detailed modeling. Proc. GT2007 ASME Turbo Expo 2007, 130, 14-17.

3. Tabacco, D.; Innarella, C.; Bruno, C. Theoretical and numerical investigation on flameless combustion. Combust. Sci. Technol. 2002, 174, 1-35. [CrossRef]

4. Lissianski, V.; Yang, H.; Qin, Z.; Mueller, M.; Shin, K.; Gardiner, W. High-temperature measurements of the rate coefficient of the $\mathrm{H}^{+} \mathrm{CO} 2 \rightarrow \mathrm{CO}^{+} \mathrm{OH}$ reaction. Chem. Phys. Lett. 1995, 240, 57-62. [CrossRef]

5. Liu, F.; Guo, H.; Smallwood, G.J. The chemical effect of $\mathrm{CO}_{2}$ replacement of $\mathrm{N}_{2}$ in air on the burning velocity of $\mathrm{CH}_{4}$ and $\mathrm{H}_{2}$ premixed flames. Combust. Flame 2003, 133, 495-497. [CrossRef]

6. Le Cong, T.; Dagaut, P.; Dayma, G. Oxidation of natural gas, natural gas/syngas mixtures, and effect of burnt gas recirculation: Experimental and detailed kinetic modeling. J. Eng. Gas Turbines Power 2008, 130, 041502. [CrossRef]

7. Meitner, P.L.; Senick, P.; Laganelli, A.; Lear, W.E. Demonstration of a Semi-Closed Cycle, Turboshaft Gas Turbine Engine. ASME Pap. 2000, 1. [CrossRef]

8. Park, J.; Kim, S.C.; Keel, S.I.; Noh, D.S.; Oh, C.B.; Chung, D. Effect of steam addition on flame structure and $\mathrm{NO}$ formation in $\mathrm{H}_{2}-\mathrm{O}_{2}-\mathrm{N}_{2}$ diffusion flame. Int. J. Energy Res. 2004, 28, 1075-1088. [CrossRef]

9. Hwang, D.J.; Choi, J.W.; Park, J.; Keel, S.I.; Ch, C.B.; Noh, D.S. Numerical study on flame structure and $\mathrm{NO}$ formation in $\mathrm{CH}_{4}-\mathrm{O}_{2}-\mathrm{N}_{2}$ counterflow diffusion flame diluted with $\mathrm{H}_{2} \mathrm{O}$. Int. J. Energy Res. 2004, 28, 1255-1267. [CrossRef]

10. Katoh, A.; Shinoda, M.; Kitagawa, K.; Gupta, A.K. Visualization of Steam Addition Effect on OH Distribution in a Flame by Isotope Shift/Planar Laser-Induced Fluorescence (IS/PLIF) Spectroscopy. J. Eng. Gas Turbines Power 2006, 128, 8-12. [CrossRef]

11. Li, M.; Tong, Y.; Thern, M.; Klingmann, J. Investigation of Methane Oxy-Fuel Combustion in a Swirl-Stabilised Gas Turbine Model Combustor. Energies 2017, 10, 648.

12. Goke, S.; Terhaar, S.; Schimek, S.; Göckeler, K.; Paschereit, C.O. Combustion of natural gas, hydrogen and bio-fuels at ultra-wet conditions. In Proceedings of the ASME 2011 Turbo Expo: Turbine Technical Conference and Exposition, Vancouver, BC, Canada, 6-10 June 2011; American Society of Mechanical Engineers: New York, NY, USA, 2011; pp. 659-670.

13. Karbasi, M.; Wierzba, I. Prediction and validation of blowout limits of co-flowing jet diffusion flames-Effect of dilution. J. Energy Resour. Technol. 1998, 120, 167-171. [CrossRef]

14. Li, M.; Tong, Y.; Thern, M.; Klingmann, J. Influence of the Steam Addition on Premixed Methane Air Combustion at Atmospheric Pressure. Energies 2017, 10, 1070. [CrossRef]

15. Kee, R.; Rupley, F.; Miller, J. Chemkin-Pro 15112; Reaction Design: San Diego, CA, USA, 2011.

16. Smith, G.P.; Golden, D.M.; Frenklach, M.; Moriarty, N.W.; Eiteneer, B.; Goldenberg, M.; Bowman, C.T.; Hanson, R.K.; Song, S.; Gardiner, W.C., Jr. GRI-Mech 3.0. Available online: http:/ / www.me.berkeley.edu / gri_mech (accessed on 15 August 2017).

17. CHMKIN-PRO 15112. ChemKin Tutorials Manual; Reaction Design: San Diego, CA, USA, 2011.

18. Walton, S.; He, X.; Zigler, B.; Wooldridge, M. An experimental investigation of the ignition properties of hydrogen and carbon monoxide mixtures for syngas turbine applications. Proc. Combust. Inst. 2007, 31, 3147-3154. [CrossRef]

19. Stöhr, M.; Boxx, I.; Carter, C.; Meier, W. Dynamics of lean blowout of a swirl-stabilized flame in a gas turbine model combustor. Proc. Combust. Inst. 2011, 33, 2953-2960. [CrossRef]

20. Boxx, I.; Stöhr, M.; Carter, C.; Meier, W. Temporally resolved planar measurements of transient phenomena in a partially pre-mixed swirl flame in a gas turbine model combustor. Combust. Flame 2010, 157, 1510-1525. [CrossRef]

(C) 2017 by the authors. Licensee MDPI, Basel, Switzerland. This article is an open access article distributed under the terms and conditions of the Creative Commons Attribution (CC BY) license (http://creativecommons.org/licenses/by/4.0/). 